\section{Análise da contaminação dos sistemas hídricos por agrotóxicos numa pequena comunidade rural do Sudeste do Brasil}

\author{
Pesticide pollution in water systems in a small \\ rural community in Southeast Brazil
}

\author{
1 Escola Nacional de Saúde \\ Pública Sergio Arouca, \\ Fundação Oswaldo Cruz, \\ Rio de Janeiro, Brasil. \\ 2 Coordenação de Programas \\ de Pós-graduação em \\ Engenharia, Universidade \\ Federal do Rio de Janeiro, \\ Rio de Janeiro, Brasil. \\ 3 Departamento de Biologia \\ Celular e Genética, \\ Universidade do Estado \\ do Rio de Janeiro, \\ Rio de Janeiro, Brasil. \\ Correspondência \\ M. M. Veiga \\ Departamento de \\ Saneamento e Saúde \\ Ambiental, Escola \\ Nacional de Saúde \\ Pública Sergio Arouca, \\ Fundação Oswaldo Cruz. \\ Rua Leopoldo Bulhões 1480, \\ 5 o andar, Rio de Janeiro, $R J$ \\ 21041-210, Brasil. \\ mveiga@ensp.fiocruz.br
}

\begin{abstract}
Recent advances in analytical techniques allow identifying pesticide pollution in water systems. In small rural communities, the negative effects of pesticide pollution can be aggravated by the lack of infrastructure and adverse socioeconomic conditions. This study investigated pesticide pollution in potential water supply sources in a tomato growing area in Paty do Alferes, Rio de Janeiro State, Brazil. The study selected 27 points where five monthly samples were collected. Pesticide pollution was determined by analyzing acetyl-cholinesterase inhibition. In 19 of the 27 sample points, some pesticide pollution was detected, and in two points the pesticide pollution was above the permitted limits. The results thus proved the incidence of pesticide pollution in water sources in Paty do Alferes that could jeopardize the local population's health.
\end{abstract}

Organosphosphorus Compounds; Carbamates; Pesticides; Water Pollutants; Contamination

\author{
Marcelo Motta Veiga ${ }^{1}$ \\ Dalton Marcondes Silva 1 \\ Lilian Bechara Elabras Veiga ${ }^{2}$ \\ Mauro Velho de Castro Faria 3
}

\section{Introdução}

Há muito tempo já se utilizavam químicos no controle de pragas da agricultura, no intuito de aumentar a produtividade agrícola. No início, utilizava-se apenas um pequeno número de compostos inorgânicos, principalmente baseados em formulações envolvendo os elementos químicos cobre e arsênio.

A partir da Segunda Guerra Mundial, visando aumentar a provisão de alimentos para atender uma explosão demográfica mundial que vinha se desenhando, houve necessidade de se buscar produtos mais eficientes. Após um lento desenvolvimento tecnológico, houve a introdução dos primeiros produtos orgânicos com a finalidade de agir como agrotóxicos, destacando-se a ação inseticida do dicloro-difenil-tricloroetano (DDT).

Este episódio deu uma nova importância aos agrotóxicos à base de compostos orgânicos no que se referia à saúde pública, tanto no aumento da produtividade agrícola quanto no controle de vetores de doenças. Porém, da mesma forma que algumas características químicas, como a persistência, eram acrescidas à função biocida dos agrotóxicos organoclorados, resultando num fator positivo para a agricultura, pois um mesmo agrotóxico eliminaria mais pragas por um período maior de tempo, também representavam maiores riscos à saúde humana e ao meio ambiente 1 . 
Só mais tarde, quando a comunidade científica passou a conhecer melhor os mecanismos de atuação dos agrotóxicos organoclorados no meio ambiente e seus efeitos à saúde humana, foi que a utilização desses agrotóxicos começou a ser substituída por agrotóxicos inibidores da acetilcolinesterase. Com essa evolução científica, os agrotóxicos organoclorados que até então cumpriam um papel fundamental no controle de pragas, foram gradativamente substituídos por agrotóxicos organofosforados e carbamatos 2,3 .

Este modelo de produção agrícola, baseado na utilização de agrotóxicos para aumento da produtividade rural, foi capaz de atender as crescentes necessidades alimentares da população. Porém, só recentemente, houve a formação de uma consciência cientifica sobre as possíveis conseqüências do uso indiscriminado de agrotóxicos na agricultura. Com isso, levantouse a hipótese de que a utilização de agrotóxicos, em certos casos, poderia gerar impactos à saúde humana e ao meio ambiente, maiores do que os benefícios associados aos seus ganhos de produtividade 1 .

Originalmente, os agrotóxicos eram estáticos, possuíam baixa solubilidade e tinham um forte poder de adesão ao solo. Com a evolução tecnológica, os agrotóxicos passaram a ser mais solúveis em água, possuir baixa capacidade de adesão e ser mais voláteis. Essas inovações tecnológicas que eram baseadas na manipulação de compostos químicos criaram agrotóxicos cada vez mais tóxicos, persistentes e eficientes para combater as pragas.

Conseqüentemente, estas alterações tecnológicas nas características químicas dos agrotóxicos também aumentaram e prolongaram ainda mais o potencial nocivo dos agrotóxicos de causar danos à saúde humana e ao meio ambiente. Por isso, existiria uma crescente preocupação dos profissionais de saúde pública com a contaminação dos sistemas hídricos por agrotóxicos, principalmente devido ao aumento do uso dos agrotóxicos nos últimos anos.

No Brasil, o consumo de agrotóxicos tem sido crescente e já está relacionado entre os países de maior consumo no mundo. O aumento na venda de agrotóxicos no Brasil entre os anos de 1991 e 1998 foi da ordem de $160 \%$. No setor agrícola, cerca de 12 milhões de trabalhadores rurais seriam expostos diariamente aos agrotóxicos. Na maioria das vezes, este trabalhador ignora as práticas adequadas sobre o manejo e uso destas substâncias químicas tornando-se o principal alvo dos seus efeitos adversos 4.

Além do mais, essas inovações tecnológicas nem sempre foram acompanhadas de estudos científicos sobre seus efeitos adversos sobre o meio ambiente e a saúde humana. Por isso, poder-se-ia afirmar que ainda não haveria fundamentação científica que sustentasse níveis seguros da presença de agrotóxicos no meio ambiente e no corpo humano.

Reconhecendo os efeitos negativos de uma potencial contaminação por agrotóxicos à saúde da população local, este estudo analisou a possibilidade de contaminação por agrotóxicos nos sistemas hídricos superficiais e subterrâneos potencialmente utilizados para consumo humano direto na região da cultura do tomate do Município de Paty do Alferes, Rio de Janeiro, Brasil.

\section{O Município de Paty do Alferes}

O Município de Paty do Alferes é caracterizado por pequenas propriedades rurais, sendo historicamente o maior produtor de tomate do Estado do Rio de Janeiro e o oitavo do Brasil. Ele possui relevo acidentado, variando de terras com altíssimo grau de suscetibilidade a terras com ligeira suscetibilidade à erosão 5,6.

A cultura do tomate é uma das mais intensivas na utilização de agrotóxicos. Uma parte significativa da economia de Paty do Alferes ainda depende dos repasses orçamentários constitucionais e de atividades intensivas em agrotóxicos.

A grande maioria dos trabalhadores rurais no Município de Paty do Alferes tem baixa instrução, o que indica uma inabilitação para o desempenho da função, uma vez que a leitura do rótulo e o entendimento dos procedimentos de preparação e aplicação seriam condições indispensáveis para o manejo e aplicação dos agrotóxicos 5 .

O município não dispõe de hospitais conveniados ao Sistema Único de Saúde (SUS), somente possui unidades ambulatoriais. Os profissionais de saúde da região não foram treinados para identificar, diagnosticar e tratar possíveis casos de intoxicação por agrotóxicos. Apesar da comunicação de casos de intoxicação por agrotóxicos ser obrigatória, não existem casos de intoxicação reportados na base de dados da Secretária Municipal de Saúde nos últimos cinco anos.

Em Paty do Alferes, grande parte da população seria de classe sócio-econômica baixa e não contando com rede de abastecimento de água tratada. Por isso, se utilizaria dos sistemas hídricos in natura como única fonte de água para consumo direto. Em 1991, uma pesquisa do IBGE revelou que mais $80 \%$ dos quase cinco 
mil domicílios do município não possuíam infra-estrutura adequada 5 .

Desta forma, os efeitos negativos da contaminação por agrotóxicos à saúde humana seriam potencializados pela falta de infra-estrutura e de condições sócio-econômicas da população exposta à contaminação.

\section{Agrotóxicos e a possibilidade de contaminação dos sistemas hídricos}

Um dos recursos mais utilizados pelos agricultores para elevar a produtividade agrícola seria o uso de agrotóxicos. Agrotóxicos quando aplicados podem contaminar o solo e os sistemas hídricos, culminando numa degradação ambiental que teria como conseqüência prejuízos à saúde e alterações significativas nos ecossistemas.

Os agrotóxicos são desenvolvidos visando potencializar suas características químicas de tal forma que sejam tóxicos a certos tipos de insetos, animais, plantas ou fungos. Embora, essa função letal dos agrotóxicos seja direcionada, estes também podem causar danos fora do seu alvo.

Com isso, os agrotóxicos que seriam compostos químicos desenvolvidos para maximizar características biocidas naturais, seriam, também, potencialmente danosos para todos os organismos vivos. O conceito de agrotóxico e afins na legislação brasileira está descrito, no artigo 1o, inciso IV do Decreto n. 4.074 de 2002 que regulamenta a Lei $n .7 .802$ de 1989.

Atualmente, os agrotóxicos mais utilizados na agricultura são os organofosforados e carbamatos, que possuem uma atividade inseticida muito eficiente, devido a sua característica de inibidor da enzima acetilcolinesterase no sistema nervoso, que tanto atua em insetos quanto em mamíferos.

No Brasil, ainda não existem dados confiáveis que retratem a realidade das intoxicações e mortes por agrotóxicos. A Organização Mundial da Saúde (OMS) estima que ocorram cerca de três milhões de intoxicações agudas por agrotóxicos anualmente no mundo, provocando um total aproximado de 220 mil mortes 7.

Até o final da década de 70, os sistemas hídricos subterrâneos eram considerados imunes à contaminação por agrotóxicos, pois se acreditava que os agrotóxicos se degradariam em partículas inofensivas ou ficariam retidos no ambiente natural antes de contaminá-los.

Recentemente, com o uso intensivo de agrotóxicos e com o avanço das tecnologias analíticas é que foi possível detectar-se a contamina- ção por agrotóxicos em sistemas hídricos. Com isso, os cientistas descobriram que os agrotóxicos, além de serem sorvidos pelo solo, poderiam acabar contaminando os sistemas hídricos.

Entretanto, ainda existe muita dificuldade de se avaliar a contaminação ambiental por agrotóxicos, principalmente em se tratando de organofosforados e carbamatos, que teriam um ciclo de vida pequeno (degradabilidade) quando comparado com organoclorados 8,9,10.

Assim, o uso de agrotóxicos e seus possíveis efeitos à saúde humana e ambiental tornaramse uma grande preocupação à comunidade cientifica, principalmente quando o recurso hídrico potencialmente contaminado seria utilizado para consumo humano 11.

Entretanto, já foi comprovado através de diversos estudos 6,12,13,14,15 que a presença de agrotóxicos nos sistemas hídricos seria mais comum do que se imaginava, principalmente nos sistemas hídricos próximos de regiões agrícolas intensivas na utilização de agrotóxicos.

A cultura do tomate no Município de Paty do Alferes, esquematizada na Figura 1, é plantada estaqueada e utilizando-se encostas bastante inclinadas. As características geomorfológicas da região quando associadas a um solo pobre e intemperizado favorecem a contaminação dos sistemas hídricos. A elevação da declividade favorece o processo de deflúvio superficial, enquanto a erosão do solo e a falta de cobertura vegetal favorecem o processo de lixiviação dos agrotóxicos.

Quando o terreno não conta com cobertura vegetal ou quando a plantação está nas fases iniciais de crescimento, existe uma maior probabilidade de contaminação dos sistemas hídricos subterrâneos. Por outro lado, a plantação mais desenvolvida conseguiria reter parte desta contaminação. Além disso, o deflúvio superficial e o transporte de agrotóxicos pelo ar atmosférico seriam possíveis fontes de contaminação dos sistemas hídricos superficiais 10 .

Outro aspecto importante no sentido de avaliar os efeitos adversos dos agrotóxicos diz respeito aos riscos de exposição. Principalmente em se tratando de pequenas propriedades rurais, é comum verificar uma proximidade inadequada das culturas agrícolas, com residências e animais domésticos. Como retratado na Figura 1, é provável que pequenas culturas intensivas na utilização de agrotóxicos estejam próximas das residências de seus proprietários, aumentando o risco de exposição.

Devido à intercomunicabilidade dos sistemas hídricos, qualquer contaminação em um determinado sistema hídrico poderia resultar em uma contaminação distante das áreas em 


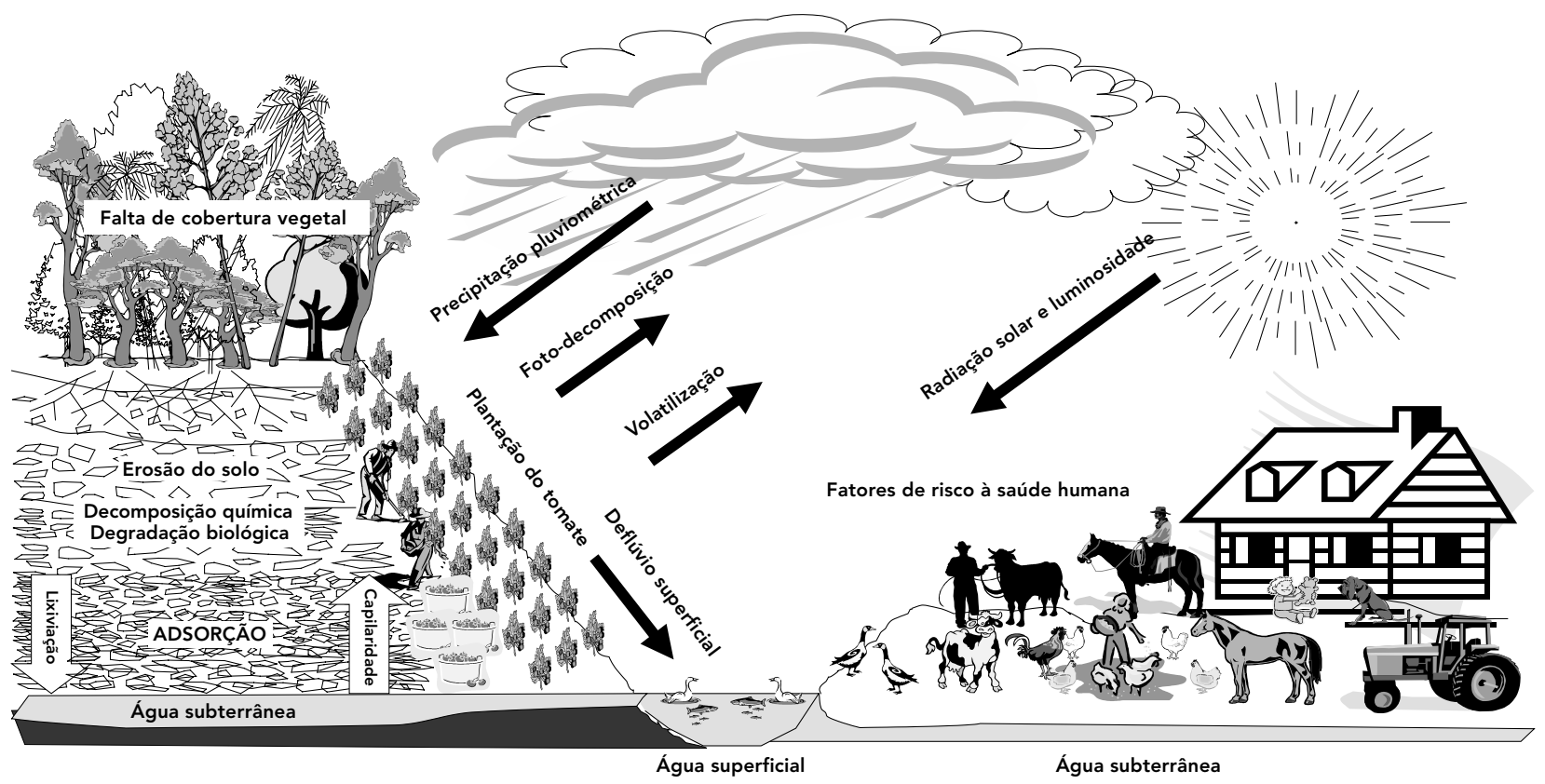

que foram originalmente aplicados. Por isso, a contaminação de um sistema hídrico não representa só a contaminação da água consumida pela população local, mas também a contaminação de toda a população abastecida por esta água contaminada 16 .

De acordo com informações obtidas no comércio de Paty do Alferes, os agrotóxicos mais utilizados na região seriam: os inseticidas organofosforados e carbomatos, alguns piretroides, agentes biológicos, agentes fisiológicos e os fungicidas.

Os efeitos adversos dos agrotóxicos à saúde dependem das características químicas, da quantidade de agrotóxicos absorvidos ou ingeridos, do tempo de exposição aos agrotóxicos e das condições gerais de saúde da pessoa contaminada. Assim, por atuarem sobre processos vitais, eles têm grande parte de seus efeitos negativos sobre a constituição física e a saúde do ser humano.

Por isso, seria importante tentar minimizar a probabilidade desses produtos tóxicos contaminarem os sistemas hídricos. Principalmente, em pequenas comunidades rurais onde os efeitos negativos dessa contaminação ainda poderiam ser potencializados. Por isso, poder-se-ia afirmar que existiria uma relação natural entre a produtividade agrícola, a degradação ambiental, o uso de agrotóxicos e os danos à saúde humana 17.

Estabeleceu-se na União Européia o valor de $0,1 \mu \mathrm{g} / \mathrm{L}$ como concentração máxima permitida de qualquer agrotóxico em águas destinadas ao consumo humano independente de sua toxicidade. O USEPA (United States Environmental Protection Agency) e a OMS estabeleceram níveis máximos individualizados por agrotóxico baseados em estudos toxicológicos e epidemiológicos. No Brasil, a legislação estabeleceu limites máximos dos contaminantes em águas dependendo do seu destino 13.

\section{Metodologia}

O objetivo deste estudo foi analisar a possível contaminação por agrotóxicos (organofosforados e carbamatos) nos sistemas hídricos superficiais e subterrâneos potencialmente utilizados para consumo humano direto na região da cultura do tomate do Município de Paty do Alferes.

O Município de Paty do Alferes foi selecionado por se tratar de uma região do Estado do 
Rio de Janeiro, com grande parte da população em área rural, com precárias condições sócioeconômicas, com solos bastante degradados, com relevo acidentado e dependente de atividades intensivas em agrotóxicos. A cultura do tomate foi selecionada por se tratar de uma produção agrícola das mais intensivas na utilização de agrotóxicos, e que nas condições existentes em Paty do Alferes só se viabilizaria através do uso de agrotóxicos. Na região estudada existem outras culturas, mas a predominância era da cultura do tomate.

Selecionaram-se 27 pontos de coleta, sendo vinte em sistemas hídricos superficiais e sete em sistemas hídricos subterrâneos, todos em localidades que não fossem atendidas por rede de abastecimento de água tratada, o que tornava esses sistemas hídricos potenciais fontes de água para consumo humano direto.

Neste estudo, financiado dentro do Programa de Pesquisa Estratégica da Fundação Oswaldo Cruz, coletou-se um total de 135 amostras para análise, correspondendo a uma coleta mensal durante cinco meses de baixa intensidade pluviométrica no período de março a setembro de 2004 , em cada um dos 27 pontos previamente selecionados.

O Município de Paty do Alferes conta com cinco microbacias, porém nem todas possuem cultura ativa de tomate. Por isso, este estudo procurou identificar os locais onde a contaminação fosse mais provável. Portanto, na seleção de pontos de coleta procurou-se abranger todas as cinco microbacias, mas, privilegiando as localidades onde a cultura de tomate estivesse ativa.

Alguns outros aspectos foram determinantes no critério de seleção dos pontos de coleta: outros pontos pré-selecionados foram excluídos, pois estavam dentro de propriedades privadas e não se obteve permissão para acesso, ou encontravam-se em localidades de difícil acesso; tentou-se privilegiar localidades com culturas ativas de tomates; e a distância e o péssimo estado das vias rodoviárias entre os pontos pré-selecionados foram outros fatores limitantes para o número e a localização dos pontos.

Normalmente, as maiores contaminações por agrotóxicos nos sistemas hídricos são identificadas após períodos chuvosos. Visando maximizar a probabilidade de detecção dos agrotóxicos e pelo fato de as coletas neste estudo não poderem ser feitas no período mais chuvoso, procurou-se fazer as coletas após alguma precipitação pluviométrica. Por isso, não houve coletas de amostras nos meses de junho e agosto, porque quase não apresentaram precipitação pluviométrica.
As coletas de amostras de águas em sistemas hídricos subterrâneos foram feitas somente em poços preexistentes. As profundidades destes poços não foram aferidas, muito embora se soubesse tratar de poços de pouca profundidade (menor do que $30 \mathrm{~m}$ ), o que indicaria possibilidade de contaminação. Poços mais profundos seriam dificilmente contaminados por organofosforados e carbamatos.

A retirada (coleta) de água dos sistemas hídricos subterrâneos se deu da mesma forma que esta água seria utilizada para consumo, ou seja, depois de ligada à bomba, deixava-se vazar água na mangueira por pelo menos um minuto e só então era feita a coleta em um frasco plástico, evitando o contato deste com objetos ao redor.

A coleta em sistemas hídricos superficiais foi feita com seqüência e locais previamente determinados. Nestas coletas tentou-se evitar a presença de sólidos em suspensão, que prejudicariam as análises. Por isso, procurou-se coletar amostras em regiões do sistema hídrico superficial que tivessem maior profundidade.

Todas as coletas (sistemas hídricos superficiais e subterrâneos) foram feitas com frascos plásticos previamente lavados, que foram novamente lavados (rinsados) no momento da coleta com a água que seria coletada, visando, assim, minimizar contaminação por fontes externas.

Após todas as coletas, as amostras eram armazenadas em bolsas térmicas contendo gelo químico, sendo que ao final do dia eram transferidas para um freezer. Essas amostras eram, então, transportadas congeladas, nas mesmas bolsas térmicas contendo gelo químico, na manhã seguinte para o laboratório onde seriam analisadas.

\section{Método analítico}

Para a determinação do teor de contaminação por agrotóxicos (organofosforados e carbamatos) nos sistemas hídricos realizou-se um convênio com o Laboratório de Toxicologia Enzimática (Enzitox), Departamento de Biologia Celular e Genética, Instituto de Biologia, Universidade do Estado do Rio de Janeiro.

O Enzitox desenvolveu uma metodologia para água e alimentos baseada em preparações da enzima acetilcolinestarase capazes de ativar os tionofosforados, possibilitando o monitoramento de todos os organofosforados e carbamatos 18 .

O método analítico desenvolvido pelo Enzitox utiliza duas formas de extração para amostras de água: o método do acetato de etila-sul- 
fato de sódio, para extração de organofosforados e carbamatos polares; e o método do diclorometano, para maioria dos organofosforados e carbamatos, excetos os que são muito polares.

A dosagem enzimática é realizada através da adição da preparação enzimática aos extratos da incubação durante 120 minutos a $37^{\circ} \mathrm{C}$, da adição do reagente iônico Triton X-100, da adição do reagente de cor ditionitrobenzoato (DTNB) e da medida do acréscimo de absorbância a cada minuto.

Comparando-se a média do extrato de água destilada (controle que corresponde a $100 \%$ de atividade enzimática) determina-se a percentagem de inibição da enzima em cada amostra. Tendo em conta a curva padrão de Metil Paration, que relaciona a porcentagem de inibição à concentração de Metil Paration, interpolamse os resultados de porcentagem de inibição na curva padrão e expressam-se os resultados em partes por bilhão (ppb) equivalentes em Metil Paration.

Portanto, um dos indicativos de contaminação de sistemas hídricos por organofosforados e carbamatos seria, então, determinado pela atividade da enzima acetilcolinesterase, de forma a avaliar a porcentagem de inibição desta, conforme estabelecido na Portaria n. 518/04 do Ministério da Saúde 19 que estabelece os valores máximos das substâncias químicas que representam risco para a saúde. O método analítico utilizado não permite segregar as eventuais contaminações por princípio ativo dos agrotóxicos, sendo uma medida agregada da presença de carbamatos e organofosforados.

Para efeito deste estudo, adotaram-se os parâmetros da legislação brasileira, onde o valor máximo permitido de contaminação é de $20 \%$ de inibição da enzima colinesterase de mamíferos, que corresponde a $10 \mu \mathrm{g} / \mathrm{L}$ em equivalentes em Metil Paration.

\section{Apresentação e análise dos resultados}

Uma informação importante, para determinar se a amostra estaria ou não contaminada, é o limite de detecção do método utilizado para análise, que neste caso é de $10 \%$ ou $5 \mu \mathrm{g} / \mathrm{L}$. Assim, resultados acima do limite de detecção podem ser considerados contaminados (contaminação detectável) muito embora estes valores ainda possam estar dentro da faixa permitida pela legislação.

A Tabela 1 apresenta um consolidado dos resultados encontrados, onde se pode verificar que nos meses de abril, maio, julho e setembro não houve valores acima do permitido pela le- gislação (máximo de 10 $\mu \mathrm{g} / \mathrm{L}$ em equivalente de Metil Paration). Contudo, em dois desses meses (maio, com quatro amostras; e setembro, com 11 amostras), houve contaminação detectável, ou seja, acima do limite de detecção do método, embora abaixo do permitido na legislação.

As células sombreadas mais claras mostradas na Tabela 1 indicam que os valores encontrados ultrapassaram o limite de detecção do método indicando uma contaminação, mas, estão dentro do limite permitido pela norma. As células sombreadas mais escuras (dois casos) indicam que estas amostras ultrapassaram, além do limite de detecção, o valor permitido pela legislação vigente.

Os sete pontos de coleta que correspondem aos sistemas hídricos subterrâneos estão indicados na Tabela 1 pelos números: 3 ; 8 ; 9; 12; 13; 22; e 27. Não houve tentativa de estratificar a análise dos resultados por tipo de sistema hídrico, uma vez que os sistemas hídricos são intercomunicáveis; os poços onde foram coletadas as amostras não são profundos; e o número de pontos de coleta (27) é relativamente pequeno.

Para o período analisado, o mês de março foi o que apresentou maior precipitação pluviométrica, e foi o único mês que apresentou duas amostras com contaminação acima do permitido pela legislação e ainda apresentou outras nove amostras com contaminação detectável, porém dentro dos valores permitidos pela legislação.

Nestas 135 coletas não houve tentativa de vínculo com a efetiva aplicação de agrotóxico por algum agricultor. Porém, sabe-se que os organofosforados e carbamatos em sistemas hídricos se degradam rapidamente, tornando bastante difícil a sua detecção depois de decorrido um determinado espaço de tempo.

Por isso, este tipo de contaminação ambiental por carbamatos e organofosforados poderia ser caracterizado como diluída, sazonal e degradável. Uma contaminação que fosse grande em um dado momento tenderia a concentrações decrescentes dos contaminantes com o passar do tempo, dependendo das condições climáticas, grau de degradabilidade do agrotóxico e do volume de água no sistema hídrico.

Portanto, para os meses analisados, dos 27 pontos de coleta selecionados, apenas em oito pontos - dois em sistemas hídricos subterrâneos e seis em sistemas hídricos superficiais -, não foram encontrados contaminação detectável pelo método utilizado. Em duas ocasiões, essas contaminações ultrapassaram, inclusive, o permitido pela legislação. 
Levando-se em conta, que o período analisado não correspondeu ao período de maior probabilidade de ocorrência de contaminação dos sistemas hídricos por agrotóxicos, os valores encontrados foram bastante significativos. Os resultados indicam que em $70 \%$ dos pontos analisados foi encontrada contaminação detectável nos meses "secos".

Nos períodos chuvosos, espera-se um aumento das pragas com um conseqüente aumento da aplicação de agrotóxicos. Os agricultores, ainda, aplicariam uma nova quantidade de agrotóxico a cada chuva mais intensa, o que significa que haveria de uma forma geral, uma maior quantidade relativa de agrotóxicos utilizados, sendo que grande parte destes agrotóxicos poderia ser carreada pela ação da chuva. Porém, devido ao aumento do risco de pragas e conseqüente queda de produtividade, existe um número menor de culturas ativas.

Deste modo, uma forma de aumentar a probabilidade de detectar contaminação nos sistemas hídricos seria coletar as amostras no período em que a aplicação de agrotóxicos coincidisse com o período de chuvas mais intensas na região (novembro a fevereiro). Este estudo sugere que futuros estudos analisem a contaminação dos sistemas hídricos por agrotóxicos durante o período chuvoso. Além disso, uma outra sugestão de estudo seria tentar coordenar as coletas de amostras com a efetiva aplicação de agrotóxicos por algum agricultor, o que não foi possível, devido ao cronograma restrito de financiamento do estudo.

Uma importante consideração é a existência de outras culturas agrícolas na região que também utilizam agrotóxicos (carbamatos e organofosforados) no seu processo produtivo. Além disso, muitos dos agrotóxicos comercializados na região são aprovados e utilizados para mais de um tipo de cultura. Desta forma, não se pôde vincular contaminação a alguma fonte produtiva específica, que no caso deste estudo seria a cultura do tomate.

Porém, a cultura do tomate é uma das mais intensivas em agrotóxicos, corresponde a maior parte da produção rural de Paty do Alferes e os pontos de coleta foram escolhidos de forma a se encontrarem próximos de culturas ativas do tomate. Por isso, no caso específico deste estudo, não seria totalmente incorreto inferir que a fonte de contaminação, principal ou talvez total, dos agrotóxicos nos sistemas hídricos fosse a cultura do tomate.

Todavia, o objetivo deste estudo foi evidenciar, de uma forma geral, a possibilidade de contaminação por carbamatos e organofosforados nos sistemas hídricos em regiões próximas de
Tabela 1

Contaminação dos sistemas hídricos por organofosforados e carbamatos.

\begin{tabular}{|c|c|c|c|c|c|c|}
\hline \multirow[t]{2}{*}{ Microbacias } & \multirow[t]{2}{*}{$\begin{array}{l}\text { Pontos } \\
\text { de coleta }\end{array}$} & \multicolumn{5}{|c|}{$\begin{array}{l}\text { Organofosforados e carbamatos totais } \\
\text { de inibição da acetilcolinesterase (\%) }\end{array}$} \\
\hline & & Março & Abril & Maio & Julho & Setembro \\
\hline \multirow[t]{10}{*}{ Bela Vista } & 1 & 5 & 0 & 13 & 2 & 10 \\
\hline & 2 & 4 & 3 & 0 & 3 & 7 \\
\hline & 3 & 9 & 0 & 4 & 0 & 9 \\
\hline & 4 & 8 & 0 & 4 & 0 & 11 \\
\hline & 5 & 6 & 3 & 9 & 0 & 10 \\
\hline & 6 & 8 & 0 & 2 & 0 & 7 \\
\hline & 7 & 2 & 0 & 4 & 0 & 5 \\
\hline & 8 & 3 & 7 & 0 & 0 & 11 \\
\hline & 9 & 0 & 6 & 16 & 0 & 10 \\
\hline & 10 & 14 & 0 & 7 & 3 & 2 \\
\hline \multirow[t]{9}{*}{ Rio Fagundes } & 11 & 13 & 0 & 1 & 5 & 13 \\
\hline & 12 & 7 & 2 & 0 & 3 & 6 \\
\hline & 13 & 22 & 0 & 0 & 0 & 7 \\
\hline & 14 & 8 & 0 & 0 & 0 & 11 \\
\hline & 15 & 10 & 0 & 15 & 0 & 13 \\
\hline & 16 & 11 & 3 & 9 & 7 & 10 \\
\hline & 17 & 0 & 1 & 0 & 0 & 0 \\
\hline & 18 & 11 & 0 & 0 & 0 & 1 \\
\hline & 19 & 17 & 0 & 0 & 4 & 4 \\
\hline Córrego do Sertão & 20 & 9 & 5 & 7 & 0 & 5 \\
\hline Ribeirão do & 21 & 4 & 5 & 5 & 0 & 8 \\
\hline \multirow[t]{2}{*}{ Secretário } & 22 & 1 & 6 & 7 & 0 & 12 \\
\hline & 23 & 12 & 0 & 13 & 0 & 6 \\
\hline Córrego da & 24 & 35 & 0 & 8 & 0 & 2 \\
\hline \multirow[t]{3}{*}{ Cachoeira } & 25 & 11 & 9 & 7 & 0 & 9 \\
\hline & 26 & 16 & 9 & 4 & 4 & 4 \\
\hline & 27 & 7 & 9 & 0 & 0 & 11 \\
\hline
\end{tabular}

Nota: as células com sombreamento claro indicam que os valores encontrados ultrapassaram o limite de detecção do método indicando uma contaminação, mas, estão dentro do limite permitido pela norma; as células com sombreamento escuras (dois casos) indicam que estas amostras ultrapassaram, além do limite de detecção, o valor permitido pela legislação vigente.

culturas onde a utilização de agrotóxicos fosse intensa e não tentar vincular especificamente a uma determinada cultura, que no caso deste estudo seria a cultura do tomate.

Logo, a principal contribuição deste estudo foi a comprovação pelos resultados apresentados, da existência de contaminação por organofosforados e carbamatos nos sistemas hídricos superficiais e subterrâneos utilizados para consumo humano direto na região da cultura do tomate no Município de Paty do Alferes.

\section{Conclusões e considerações finais}

O modelo de produção agrícola baseado na utilização de agrotóxicos para aumento da produ- 
tividade agrícola teria como resultado uma série de conseqüências adversas à saúde humana e ao meio ambiente, que muitas vezes poderiam ultrapassar as vantagens associadas a seu ganho de produtividade.

A hipótese central deste estudo foi que uma parte dos agrotóxicos aplicados na agricultura não seria completamente retida pelas plantas, sorvida pelo solo ou teriam suas moléculas decompostas pelo sol, por microorganismos existentes no solo ou através de reações químicas, podendo contaminar os sistemas hídricos.

Os resultados apresentados neste estudo mostraram que $70 \%$ dos pontos de coleta selecionados apresentaram contaminação detectável, o que validou a hipótese de que os agrotóxicos quando aplicados na agricultura podem contaminar os sistemas hídricos superficiais e subterrâneos.

Por esses resultados, ficou comprovada a contaminação por agrotóxicos nos sistemas hídricos superficiais e subterrâneos potencialmente utilizados para consumo humano direto na região da cultura do tomate no Município de Paty do Alferes.

Contudo, alguns efeitos negativos dessa contaminação dos sistemas hídricos por agrotóxicos seriam potencializados em municípios com condições semelhantes a Paty do Alferes, onde grande parte da população rural local não conta com rede de abastecimento regular de água; com infra-estrutura adequada; com con- dições sócio-econômicas favoráveis; e ainda, possui um sistema de saúde deficiente.

Algumas das possíveis soluções visando reduzir essa possibilidade de contaminação dos sistemas hídricos seriam: proteção das fontes de água subterrâneas e superficiais; gestão e manuseio dos agrotóxicos em áreas de produção rural; regulação estatal; educação ambiental; e adoção de práticas que minimizem os danos ao meio ambiente e a saúde humana.

No entanto, qualquer proposta de intervenção deveria passar por programas de educação visando à mudança de comportamento do trabalhador rural com relação ao manejo e utilização do agrotóxico. Para isso, seria necessário que qualquer ação seja planejada de forma participativa, envolvendo de forma sinérgica a comunidade e o poder público local em todo o processo decisório.

Além disso, dever-se-ia incentivar a adoção mais responsável das novas tecnologias de agrotóxicos, ou seja, o desenvolvimento de agrotóxicos deveria ser acompanhado pela evolução do conhecimento dos mecanismos de atuação desses agrotóxicos no meio ambiente e na saúde humana.

Dever-se-ia, ainda, estimular práticas mais sustentáveis de gestão do uso e do descarte dos agrotóxicos, o que contribuiria, inclusive, para mitigar possíveis efeitos negativos da presença desses agrotóxicos no meio ambiente e no corpo humano.

\section{Resumo}

Só recentemente, com a evolução das técnicas analíticas foi possível a detecção de contaminação por agrotóxicos nos sistemas hídricos. Em pequenas comunidades rurais, os efeitos negativos à saúde pública de uma contaminação dos sistemas hídricos seriam agravados pela falta de infra-estrutura e de condições sócio-econômicas. O objetivo deste estudo foi analisar essa possível contaminação por agrotóxicos nos sistemas hídricos superficiais e subterrâneos utilizados para consumo humano direto na região da cultura do tomate no Município de Paty do Alferes, Rio de Janeiro, Brasil. Para isso, este estudo selecionou 27 pontos de coleta, onde foram feitas cinco coletas mensais, perfa-

zendo um total de 135 amostras. A contaminação de sistemas hídricos por organofosforados e carbamatos foi determinada pela análise da inibição da atividade da enzima acetilcolinesterase. $O$ resultado encontrado foi que em 19 dos 27 pontos selecionados houve contaminação detectável, sendo que em duas ocasiões essas contaminações ultrapassaram o permitido pela legislação. Com isso, comprovou-se a contaminação dos sistemas hídricos na região de Paty do Alferes, o que colocaria a saúde da população local em risco.

Compostos Organofosforados; Carbamatos; Praguicidas; Poluentes da Água; Contaminação 


\section{Colaboradores}

Todos os autores fizeram parte da equipe que atuou no projeto financiado pelo programa de pesquisa estratégica da Fundação Oswaldo Cruz, que deu origem a este artigo. M. M. Veiga coordenou o projeto, foi responsável pela redação do artigo e colaborou em todas as partes do artigo (referencial teórico, metodologia, discussão e análise dos resultados). D. M. Silva contribuiu na metodologia, análises químicas e discussão dos resultados; atuando também, como revisor do texto. L. B. E. Veiga colaborou no referencial teórico (impactos à saúde humana e ao meio ambiente) e na metodologia. M. V. C. Faria participou na metodologia, discussão e análise dos resultados e coordenou as análises químicas.

\section{Referências}

1. Tomita RY, Beyruth Z. Toxicologia de agrotóxicos em ambiente aquático. Biológico 2002; 64:135-42.

2. International Programme on Chemical Safety/ United Nations Environment Programme/International Labour Organisation/World Health Organization. Environmental health criteria for carbamate pesticides: a general introduction. Geneva: World Health Organization; 1986.

3. International Programme on Chemical Safety/ United Nations Environment Programme/International Labour Organisation/World Health Organization. Environmental health criteria for organophosphorous insecticides: a general introduction. Geneva: World Health Organization; 1986

4. Oliveira-Silva JJ, Meyer A. O sistema de notificação das intoxicações: o fluxograma da joeira. In: Peres F, Moreira JC, organizadores. É veneno ou remédio? Agrotóxicos, saúde e ambiente. Rio de Janeiro: Editora Fiocruz; 2003. p. 317-26.

5. Coutinho JAG. Uso de agrotóxicos no município de Paty do Alferes: um estudo de caso. Caderno de Geociências 1994; 10:23-31.

6. Ramalho JFGP, Amaral Sobrinho NMB, Velloso ACX. Contaminação da microbacia de caetés com metais pesados pelo uso de agroquímicos. Pesq Agropec Bras 2000; 35:1289-303.

7. Organização Pan-Americana da Saúde. Manual de vigilância da saúde de populações expostas a agrotóxicos. Brasília: Organização Pan-Americana da Saúde; 1996.

8. Landon M, Jacobsen J, Johnson G. Pesticide management for water quality protection. Bozeman: Montana State University; 1990.

9. Instituto Brasileiro de Geografia e Estatística. Indicadores de desenvolvimento sustentável. Rio de Janeiro: Instituto Brasileiro de Geografia e Estatística; 2002. (Estudos e Pesquisas Informação Geográfica, 2).

10. Buttler T, Martinkovic W, Nesheim ON. Factors influencing pesticide movement to ground water. Gainesville: University of Florida/Institute of Food and Agricultural Services; 1998.

11. Wisconsin State Laboratory of Hygiene. Pesticides in drinking water. http://www.slh.wisc.edu/ehd/ pamphlets/pesticide.php (acessado em Mar/2005).

12. Governo do Estado do Rio de Janeiro. Programa estadual de investimentos da bacia do Rio de Janeiro: poluição por fontes difusas. Sub-região B. Rio de Janeiro: Secretaria de Estado de Meio Ambiente/Fundação Superintendência Estadual de Rios e Lagoas; 1998.

13. Dores EFGC, De-Lamonica-Freire EM. Contaminação do ambiente aquático por pesticidas. Estudo de caso: águas usadas para humano em Primavera do Leste, Mato Grosso - análise preliminar. Quím Nova 2001; 24:27-36.

14. Pesticide Action Network UK. Pesticides in water: costs to health and the environment. London: Pesticide Action Network UK; 2000. (Briefing Paper, 1).

15. Lind P. Poisoned waters: pesticide contamination of waters and solutions to protect Pacific salmon. Eugene: Northwest Coalition for Alternatives to Pesticides; 2002.

16. Peres F, Moreira JC, Dubois GS. Agrotóxicos, saúde e ambiente: uma introdução ao tema. In: Peres F, Moreira JC, organizadores. É veneno ou remédio? Agrotóxicos, saúde e ambiente. Rio de Janeiro: Editora Fiocruz; 2003. p. 21-41.

17. Waswa F, Gachene CKK, Eggers H. Assessment of erosion damage in Ndome and Ghazi, Taita Taveta, Kenya: towards an integrated erosion management approach. GeoJournal 2002; 56:171-6.

18. Castro-Faria MV. Avaliação de ambientes e produtos contaminados por agrotóxicos. In: Peres F, Moreira JC, organizadores. É veneno ou remédio? Agrotóxicos, saúde e ambiente. Rio de Janeiro: Editora Fiocruz; 2003. p. 177-209.

19. Brasil. Ministério da Saúde. Portaria n. 518 de 25 de março de 2004 que estabelece os procedimentos e responsabilidades relativos ao controle e vigilância da qualidade da água para consumo humano e seu padrão de potabilidade, e dá outras providências. Diário Oficial da União 2004; 26 mar.

Recebido em 11/Jul/2005

Versão final reapresentada em 08/Fev/2006

Aprovado em 14/Fev/2006 